\title{
NK/T Lymphoma of Nasal-Type in a Patient with an HIV Infection
}

\author{
Cobos Quevedo Orestes de Jesús*1, Rentería Guevara Cynthia ${ }^{1}$, Hernández Ceja Paulina ${ }^{1}$, Del Ángel Hernández \\ Mariela $^{1}$ and Ramírez Montelongo Sandra María ${ }^{2}$
}

${ }^{1}$ Internal Medicine Service, México

${ }^{2}$ Head of Internal Medicine Service, México

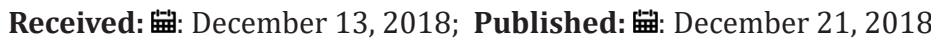

*Corresponding author: Cobos Quevedo Orestes de Jesús, Department of Internal Medicine, IMSS (Mexican Institute of Social Security), Zone 27 General Hospital, Mexico

\begin{abstract}
NK/T lymphoma of nasal-type is a rare affection associated with a bad prognosis, it was described in 1933 as a malignant midfacial granuloma Its diagnosis depends on clinical suspicion and its confirmed by immunohistopathological [1]. There has been found association between this affection and infection by human immunodeficiency virus [2]. The clinical case presented is of a 48 year old, male patient with NK/T lymphoma of nasal-type and HIV infection.
\end{abstract}

Keywords: Case Report; Nasal Lymphoma; Natural-Killer; HIV

\section{Introduction}

The NK/T lymphoma of nasal-type it's a rare disease, presented more frequently in men between the ages of 50 and 60 years old [3], they represents almost 6-7 \% of all nonhodgkin's lymphoma (NHL) and it's mostly found in regions like the Southeast of Asia, this percentage changes in the United States reaching $1.5 \%$, in Mexico there has been reports of a high prevalence in respect to other regions, nevertheless more precise statistics are needed $[4,5]$. There's a lot unknown in respect to its etiopathogenesis and it comprehends a variety of oncogenic paths, its development is associated invariably to the Epstein-Barr Virus [6]. The diagnosis of such disease is made after clinical suspicion, they can have nasal obstructive symptoms, necrotic lesions and diverse upper airway symptoms by compression of adjacent structures and general symptoms, the approach covers a broad spectrum of extensive studies where we can highlight the PET scan $[6,7]$. The golden standard are the morphological findings (polymorphic infiltration of atypical lymphoid) and immunohistochemistry (CD2, CD56, cytoplasmic CD3, granzyme B, TIA-1, and perforina) taking from 6 to 8 biopsies from different places due to the usual existing necrosis and if possible identify the charge of the Epstein-Barr virus that also has a biomarker prognosis implication [5,8]. Regarding treatment there're still research about it, in phase I/II studies the preference is a combination of radiation therapy with chemotherapy [3].
For phase III/IV studies Chemotherapy is the foundation of the treatment. The principal agent in Chemotherapy is L-asparaginase, currently there are no conclusive data about immunotherapy or hematopoietic Stem cells [6,8]. The role of the human immunodeficiency virus in combination with said neoplasia seems to cause a rapid progression of the disease without definition of the etiopathogenic paths, there exist only a few reported cases $[9,10]$.

\section{Case Presentation}

Mexican male of 48 years old without oncological family history, without precedents of chronic diseases or use of medicines and denial of history of STDs risk, goes to check up due to progressive dysphagia to solids, halitosis, nasal voice, nausea, fever, weight loss of over $10 \%$ body weight, asthenia and adynamia. Oral cavity exploration with necrotic ulcer in soft palate, posterior green-greenis discharge, congestive turbinates, otoscopy revealed hypomobility of both tympanic membranes, rest of exam without relevant foundings. Laboratory studies reveal pancytopenia. Tomography reveals enlargement of the mucous of the left maxillary antrum, the ethmoidal cells and the left sphenoid sinus; In abdomen the image revealed multiple renal calcifications and splenomegaly. ELISA and Western Blot positive for HIV. A biopsy of the nasopharyngeal tumor is taken and it reports NK/T lymphoma of nasal-type with positive 
CD-56. During Hospital stay the diagnostic and therapeutically approach are limited due to septic shock due a pulmonary infection with a torpid evolution and the patient dies in the IC unit Figure 1.

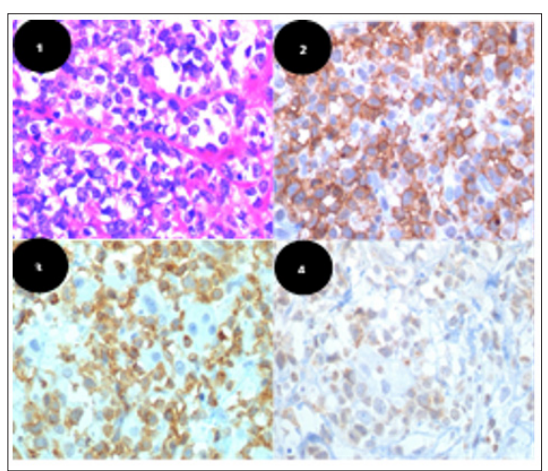

Figure 1:

a) Cellular infiltrate of atypical lymphocytes. 40x lense

b) Ocre halo around the lymphocyte, positive staining CD56 +

c) $\mathrm{CD} 8+$

d) LMP 1+, membrane antigen associated with EB virus infection.

\section{Discussion}

The NK/T lymphoma of nasal-type is a rare affection associated with a bad prognosis, it was described in 1933 as a malignant midfacial granuloma and since 2016 is being referred with the modern nomenclature by the World Health Organization (WHO) in its classification of lymphoid malignancies, it constitutes from 1.5 to $7 \%$ of all non-Hodgkin lymphomas and presents a marked prevalence in some areas like Southeast Asia and Central America $[4,5,8]$. Usually it produces nasal obstruction due to invasion of sinuses and nasal cavities, it can coexist with epistaxis, nasal discharge, odynophagia and general symptoms. The emphasis on suspicion and intentional diagnosis radícate in the importance of early treatment $[4,6]$. It is more frecuente in males and the sixth decade of live [3]. Histologically the cells show a pattern of angiocentric growth, which causes vascular obstruction and necrosis, immunophenotypically, the tumor's cell show CCD2, CD56, cytoplasmic CD3, granzyme B, TIA-1, and perforina [68]. Characteristically i invades middle line structures and its bad prognosis has reported grave and fast progression when associated with HIV infection [9-11]. Even though some of its etiopathogenesis mechanisms are known, and the invariable relation to EB virus [6], there's still a lot of information lacking on the lymphotropic role of HIV. The intermediate and high grade lymphomas are the most frequent ones in HIV patients, the frecuente can increase up to 165 times in comparison to immunocompetent [10], In that regard there are some cases in which association with NK/T lymphomas has not been found as reported by Catteneo et al., Nevertheless the role of EBV is not frequent in immunocompetent patients [12], which is why most fatalities can be associated to a synergy of viral mechanisms and a state of immunosuppression. It's important to broaden the study of such a cases to anodize the variables that could interfere with the correct statistic rigor to determine possible associations. The lack of information on the subject could affect the survival or complications of the patients such as the one presented.

\section{Conclusion}

It's unknown in its entirety the pathogenesis of the NK/T nasal-type extranodal lymphoma cells, it is known that is strongly associated with the infection of Epstein-Barr virus and a more aggressive course in immunocompromised patients, like in this case, there should be more research to determine if there is a pathogenic relation between TNK lymphoma and HIV to explain the results found in the literature.

\section{Acknowledgment}

The authors wish to express their sincere gratitude to our patient's family for their patience and cooperation. Adriana Ledesma Garcia for translating this text.

\section{References}

1. Doh K, Tagba E, Thiam I, Sarr A, Woto Gaye G (2016) Lymphome T/ NK de type nasal : une pathologie rare de mauvais pronostic. Revue de Stomatologie, de Chirurgie Maxillo-Faciale et de Chirurgie Orale 117(3): 167-169.

2. Meister A, Hentrich M, Wyen C, Hübel K (2018) Malignant lymphoma in the HIV-positive patient. European Journal of Haematology, 101(1): 119-126.

3. Riet FG, Canova CH, Gabarre J, Ben Hassine S, Kamsu Kom L, et al. (2014) Radiothérapie des lymphomes NK/T localisés aux fosses nasales. Cancer/Radiothérapie 18(2): 147-153.

4. Kidwai SM, Parasher AK, Lin FY (2015) An unusual presentation of NK/ T-cell lymphoma, nasal-type in the United States. American Journal of Otolaryngology 36(1): 80-83.

5. Labardini (2011) Oncoguía: Linfoma No Hodgkin. Cancerología 6: 139152.

6. Tse E, Kwong YL (2016) Diagnosis and management of extranodal NK/T cell lymphoma nasal type. Expert Review of Hematology 9(9): 861-871.

7. Taali L, Abou Elfadl M, Fassih M, Mahtar M (2017) Nasal NK/T-cell lymphoma: A tragic case. European Annals of Otorhinolaryngology, Head and Neck Diseases 134(2): 121-122.

8. Tse E, Kwong YL (2017) The diagnosis and management of NK/T-cell lymphomas. Journal of Hematology \& Oncology 10(1).

9. Cobo F, Talavera P, Busquier H, Concha Á (2007) CNK/T-cell brain lymphoma associated with Epstein-Barr virus in a patient with AIDS. Neuropathology 27(4): 396-402.

10. Gutiérrez Alvarado, Daniel Hernández González, Diana Gil Enriquez, Fernando Pacheco Uc, Dayana Williams (2015) Linfoma nasal de células T/NK. Evid Med Invest Salud 8(2): 89-92.

11. Panarelli NC, Furman RR, Wang YL, Elstrom R, Cohen JA, et al. (2010) NK/T cell non-Hodgkin lymphoma in a HIV-positive patient. Journal of Hematopathology 3(1): 35-40.

12. Cattaneo C, Facchetti F, Re A, Borlenghi E, Majorana A, et al. (2005) Oral cavity lymphomas in immunocompetent and human immunodeficiency virus infected patients. Leukemia \& Lymphoma 46(1): 77-81. 
ISSN: 2574-1241

DOI: $10.26717 / B J S T R .2018 .12 .002263$

Cobos Quevedo Orestes de Jesús. Biomed J Sci \& Tech Res

(c) (i) This work is licensed under Creative

Submission Link: https://biomedres.us/submit-manuscript.php

$\begin{array}{ll}\text { BIOMEDICAL } & \text { Assets of Publishing with us } \\ \text { RESEARCHES } & \text { - Global archiving of articles } \\ \text { - Immediate, unrestricted online access }\end{array}$

